\title{
A comparative study on the effect of different activating solutions and formulations on the early stage geopolymerization process
}

\author{
Lais Alves ${ }^{1, *}$, Nordine Leklou ${ }^{2}$, and Silvio de Barros ${ }^{1,3}$ \\ ${ }^{1}$ Federal Center for Technological Education CEFET/RJ, 20271-110, Rio de Janeiro, Brazil \\ ${ }^{2}$ University of Nantes, Research Institute of Civil and Mechanic Engineering, 44600, Saint Nazaire, \\ France \\ ${ }^{3}$ GeM Institute, UMR 6183 CNRS, CESI, Saint-Nazaire, France
}

\begin{abstract}
Concrete is a major construction material that produces high levels of carbon dioxide in its manufacturing process. Hence the construction sector is responsible for relevant environmental impacts. This justifies the need to find materials as green and ecological alternatives to common Portland cement. Geopolymers represent the most promising alternative due to its proven durability, mechanical and thermal properties. This study investigates the effects of solid-to-liquid and alkali activator ratios on the synthesis of slag-based pure geopolymer and their relation to the geopolymerization process. Two activating solutions were used: a) a mixture of sodium hydroxide, sodium silicate, and water; and b) a mixture of potassium hydroxide solution, potassium silicate, and water. As precursor material, ground blast furnace slag was used. Precursors and activators were mixed with solid-to-liquid ratios in range of 1.5 to 2.2. In the first stage of the study, the mechanical properties were evaluated for each activating solution. In the following stage, different formulations, with variations in the water percentage and solid-to-liquid ratio were tested for mechanical properties and SEM observations. Test results indicate that the resulting geopolymer has the potential for high compressive strength and is directly affected by the composition of the activating solution. It can also be observed that compressive strength was affected by solid-to-liquid ratio and $\%$ of water added to the mixture, and strength increased with ageing day.
\end{abstract}

\section{Introduction}

In construction, concrete is one of the most widely used substances in the world and requires large amounts of Portland cement, which produces large amounts of carbon dioxide $\left(\mathrm{CO}_{2}\right)$. Thus, with this very significant detriment to the environment, comes the importance of innovative and alternative ways of substituting this material [1]. Geopolymers appear as an alternative option that not only offers less risk to the

\footnotetext{
*Corresponding author: lais.alves@ cefet-rj.br
} 
environment, but also has good mechanical properties that make them a building material of great need for future study and projection [2].

Geopolymer is a mixture based on polysiloxosialate, which is an aluminosilicate (Al-Si$\mathrm{O}$ ), sodium, potassium and calcium (Na, K, Ca-PSS) compound and has high mechanical strength, durability and surface hardness [3]. Geopolymers exhibit a wide variety of properties and characteristics depending on precursor material selection and mixture conditions [4]. Based on the composition used, it is able to acquire other properties such as higher initial resistance [5], chemical resistance and refractoriness [6]. Although they behave similarly to organic polymers, i.e. the ability to stabilize at low temperatures and in a short time, geopolymers are harder, inorganic, stable and non-flammable at temperatures up to $1250^{\circ} \mathrm{C}[7]$.

Several researches have been carried out to investigate the physical properties, mechanical properties, characterization and the durability of the geopolymers by using the source materials such as fly ash [8,9], slag [10,11] and metakaolin [12, 13]. Benefits of these materials may include long term durability [14], low shrinkage [15], adhesive application [16], higher mechanical strength [17], high acid resistance [18-20], low thermal conductivity [21], among others.

Regarding the effect of the alkaline activator, Duxson et. al [22] associated the mechanical properties of geopolymer to the alkali cation $(\mathrm{Na}+$ or $\mathrm{K}+$ ) and the $\mathrm{Si} / \mathrm{Al}$ molar ratio. Activating solutions can be sodium silicate, sodium hydroxide, potassium silicate, potassium hydroxide and other alkaline salts [23-29]. Hardjito and Rangan [30] reported that compressive strength increased when both $\mathrm{S} / \mathrm{L}$ ratio and $\mathrm{Na}_{2} \mathrm{SiO}_{3} / \mathrm{NaOH}$ ratios increased, thus the ratios influenced the workability of geopolymers.

This study aims to investigate the possibility of using slag-based geopolymer as an alternative construction material. Based on the type of activating solution used and the geopolymerization process for different formulations, the mechanical strengths in flexion and compression and the curing conditions are assessed. The first phase of the research investigated the macrostructure of the different mixtures, in order to select the best formulation for the geopolymer. Following, different percentages of the activating solution were tested, in relation to the flexural and compressive strength, shrinkage and Young modulus, to test the silicate-to-aluminium $(\mathrm{Si} / \mathrm{Al})$ ratio on geopolymer synthesis. Duxson et. al $[31,32]$ observed that the strength increased as the $\mathrm{Si} / \mathrm{Al}$ molar ratio increased for metakaolin geopolymer, from 1.15 to 1.90 . In this study, for slag-based geopolymer, the $\mathrm{Si} / \mathrm{Al}$ ratio was fixed at 2.6.

To gain further insight, the microstructure was then observed by Scanning Electron Microscopy (SEM). The results confirm that the activating solution has a significant effect on the resulting geopolymer. It can also be observed that the different percentages of water and solid-to-liquid ratio directly affect the compressive strength. These results make possible to anticipate the mechanical performance levels and physical characteristics depending on the formulation of the slag-based geopolymer to evaluate possible applications.

\section{Materials and methods}

\subsection{Precursor material}

Ground blast furnace slag (GBFS) was used as precursor material, source of silica and alumina, for the fabrication of geopolymers. The chemical compositions can be found in Table 1. Blast furnace slag is produced by drying and grinding granulated blast furnace slag. It was provided by ECOCEM from France. The degree of depolymerisation (DP) is an 
indicator of slag activity, where a good DP ranges from 1.3 to 1.5 [33]. An important characteristic is $\mathrm{D}_{50}$, a typical feature used to represent the average particle size in the production and application of powder materials. According to Lateef et. al (2016) [34] a large surface area leads to a higher polymerization rate and a difference in the number of voids, that can affect the durability of the geopolymer. For the slag used, DP was found 1.44 and $\mathrm{D}_{50}=11.8 \mu \mathrm{m}$.

Table 1. Chemical composition of precursors.

\begin{tabular}{|c|c|c|c|c|c|c|c|c|c|c|}
\hline $\mathbf{C a O}$ & $\mathrm{SiO}_{2}$ & $\mathrm{Al}_{2} \mathrm{O}_{3}$ & $\mathbf{F e}_{2} \mathrm{O}_{3}$ & $\mathbf{M g O}$ & $\mathbf{K}_{2} \mathrm{O}$ & $\mathbf{N a}_{2} \mathrm{O}$ & $\mathbf{S O}_{3}$ & $\mathbf{T i O}_{2}$ & $\mathbf{M n O}$ & $\mathbf{L O I}$ \\
\hline 43.2 & 37.2 & 10.5 & 0.6 & 7 & - & 0.6 & 0.1 & 0.5 & 0.3 & 0.7 \\
\hline
\end{tabular}

\subsection{Activating solutions}

The alkaline activating solution employed in the mixtures, in its proper proportions, were prepared by mixing an alkali hydroxide $(\mathrm{MOH})$ solution with an alkali silicate $\left(\mathrm{M}_{2} \mathrm{SiO}_{3}\right)$ solution, $\mathrm{M}$ being sodium $(\mathrm{Na})$ or potassium $(\mathrm{K})$. Three parameters control the molarity of produced activator oxides, the concentration of $\mathrm{MOH}$ solution, $\mathrm{M}_{2} \mathrm{O} / \mathrm{SiO}_{2}$ molar ratio, and $\left(\mathrm{M}_{2} \mathrm{O}+\mathrm{SiO}_{2}\right)$ percentage by mass in used $\mathrm{M}_{2} \mathrm{SiO}_{3}$ solution and ratio of $\mathrm{M}_{2} \mathrm{SiO}_{3} / \mathrm{MOH}$ by mass. After preparing the solutions, both were kept for at least 24 hours in ambient conditions. The chemical composition for alkali-silicate products can be observed in Table 2.

Table 2. Composition of alkali-silicate products (percentage by mass).

\begin{tabular}{|c|c|c|}
\hline Oxides & $\mathbf{K}_{2} \mathrm{SiO}_{3}$ & $\mathbf{N a}_{2} \mathrm{SiO}_{3}$ \\
\hline $\mathrm{M}_{2} \mathrm{O}$ & 28.6 & 8.0 \\
\hline $\mathrm{SiO}_{2}$ & 71.4 & 27.0 \\
\hline $\mathrm{H}_{2} \mathrm{O}$ & - & 65.0 \\
\hline
\end{tabular}

Potassium silicate activator $(\mathrm{K}-\mathrm{Si}$ ) is prepared by mixing $10 \mathrm{M}$ potassium hydroxide solution $(\mathrm{KOH})$ and potassium silicate solution $\left(\mathrm{K}_{2} \mathrm{SiO}_{3}\right)$, with $2 \mathrm{~K}_{2} \mathrm{SiO}_{3} / \mathrm{KOH}$ mass ratio. Sodium silicate activator $(\mathrm{Na}-\mathrm{Si}$ ) was prepared by mixing $10 \mathrm{M}$ sodium hydroxide solution $(\mathrm{NaOH})$ and sodium silicate $\left(\mathrm{Na}_{2} \mathrm{SiO}_{3}\right)$ solution, with $2 \mathrm{Na}_{2} \mathrm{SiO}_{3} / \mathrm{NaOH}$ mass ratio, as described in 35 . The produced Na-silicate activator contained $66.7 \%$ water with 0.7 $\mathrm{Na}_{2} \mathrm{O} / \mathrm{SiO}_{2}$ molar ratio. K-silicate activator contained $53.5 \%$ water with $0.76 \quad \mathrm{~K}_{2} \mathrm{O} / \mathrm{SiO}_{2}$ molar ratio. These are user-friendly activator solutions, with $\mathrm{M}_{2} \mathrm{O} / \mathrm{SiO}_{2}$ molar ratio less than 0.7836 .

$\mathrm{KOH}$ and $\mathrm{NaOH}$ were purchased from ALFA-AESAR in the form of pellets, white coloured with $85 \%$ and $98 \%$ purity, respectively. Potassium silicate $\left(\mathrm{K}_{2} \mathrm{SiO}_{3}\right)$ was purchased from Fisher Scientific in the form of white powder, with $2.5 \mathrm{SiO}_{2} / \mathrm{K}_{2} \mathrm{O}$ mass ratio. Sodium silicate $\left(\mathrm{Na}_{2} \mathrm{SiO}_{3}\right)$ was purchased from VWR in soluble form, of $\mathrm{pH}$ between $11-11.5$ and density $1.35 \mathrm{~g} / \mathrm{cm}$ at $20^{\circ} \mathrm{C}$.

\subsection{Casting and curing}

Geopolymerisation process can be described as chemical reactions between aluminosilicates with soluble silicates under high alkalinity, which yield $\mathrm{Si}-\mathrm{O}-\mathrm{Al}-\mathrm{O}$ bonds. As described earlier, the first stage of the study was to investigate the effect of the activating solution type in the geopolymerization process. As the first step, the test matrix 
contained four different sets of replicates, as show in Table 3. The water percentage $\left(\mathrm{H}_{2} \mathrm{O}\right.$ summed with water in the activating solution) was tested empirically, following recommendations from different researches, to obtain desired workability. Solid-to-liquid ratio ranged from 2.0 to 2.2 , as done by 35 .

Table 3. Different set of test mixtures.

\begin{tabular}{|l|l|l|l|l|l|l|}
\hline Mixture & $\begin{array}{l}\mathbf{N a - S i} \\
\left(\mathbf{k g} / \mathbf{m}^{\mathbf{3}}\right)\end{array}$ & $\begin{array}{l}\mathbf{K}-\mathbf{S i} \\
\left(\mathbf{k g} / \mathbf{m}^{\mathbf{3}}\right)\end{array}$ & $\begin{array}{l}\mathbf{G B F S} \\
\left(\mathbf{k g} / \mathbf{m}^{\mathbf{3}}\right)\end{array}$ & $\begin{array}{l}\mathbf{H} \mathbf{O} \\
\left(\mathbf{k g} / \mathbf{m}^{\mathbf{3}}\right)\end{array}$ & \% water & $\begin{array}{l}\text { Solid/ } \\
\text { Liquid }\end{array}$ \\
\hline GBFS_Na-Si_2.2 & 338.5 & - & $1,432.3$ & 260.4 & 23.7 & 2.2 \\
\hline GBFS_NaOH_2.0 & 335.3 & - & $1,458.3$ & 208.3 & 21.3 & 2.0 \\
\hline GBFS_KOH_2.0 & - & 335.3 & $1,458.3$ & 208.3 & 10.4 & 2.0 \\
\hline GBFS_K-Si_2.2 & - & 338.5 & $1,432.3$ & 260.4 & 12.8 & 2.2 \\
\hline
\end{tabular}

The precursor material was mixed for three minutes in order to have a more homogeneous mixture. Following, the activating solution mixed with the water was added to the dry mixture and blended for three minutes more. The samples were cured at $20{ }^{\circ} \mathrm{C}$ and 50\% humidity, sealed with a plastic film. Three prismatic specimens of $40 \times 40 \times 160$ $\mathrm{mm}$ were fabricated for testing for each activating solution, in the desired age, according to EN 196-1. First, the 3-point-bending test was performed, and with each half prism, compression strength was measured to verify the feasibility for the following stages with early age mechanical tests.

The second phase consisted of investigating the effects of variations of water percentage and solid-to-liquid ratios. $\mathrm{SiO}_{2} / \mathrm{Al}_{2} \mathrm{SO}_{3}$ ratio was fixed at 2.6, $\mathrm{Na}_{2} \mathrm{O} / \mathrm{Al}_{2} \mathrm{SO}_{3}$ ratio at 0.8 and $\mathrm{H}_{2} \mathrm{O} / \mathrm{Na}_{2} \mathrm{O}$ ratio was kept between 9.2 and 9.7. Three specimens of each type of

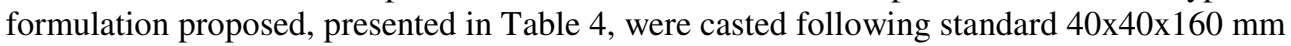
dimensions, to test for compression and flexural strength at 7, 14, 28, 90 and 120 days. The same mixture procedure explained was followed for this stage. The effect of the different parameters is discussed in the next section, along with the results of the essays.

Table 4. Mixtures for second phase.

\begin{tabular}{|c|c|c|c|c|c|c|}
\hline Mixture & $\begin{array}{l}\mathrm{Na}-\mathrm{Si} \\
\left(\mathrm{kg} / \mathbf{m}^{3}\right)\end{array}$ & $\begin{array}{l}\text { K-Si } \\
\left(\mathbf{k g} / \mathbf{m}^{3}\right)\end{array}$ & $\begin{array}{l}\text { GBFS } \\
\left(\mathrm{kg} / \mathbf{m}^{3}\right)\end{array}$ & \begin{tabular}{|l|}
$\mathrm{H}_{2} \mathrm{O}$ \\
$\left(\mathrm{kg} / \mathrm{m}^{3}\right)$
\end{tabular} & $\%$ water & $\begin{array}{l}\text { Solid/ } \\
\text { Liquid }\end{array}$ \\
\hline GBFS_Na-Si_2.2 & 338.5 & - & $1,432.3$ & 260.4 & 23.7 & 2.2 \\
\hline GBFS_Na-Si_2.0 & 335.3 & - & \begin{tabular}{|l|}
$1,458.3$ \\
\end{tabular} & 208.3 & 21.3 & 2.0 \\
\hline GBFS_Na-Si_1.5 & 488.3 & - & \begin{tabular}{|l|}
$1,464.8$ \\
\end{tabular} & 244.1 & 25.6 & 1.5 \\
\hline
\end{tabular}

\section{Results and discussion}

\subsection{Effect of activating solution type on mechanical properties}

To investigate the effect of the type of activating solution, specimens were fabricated with $\mathrm{NaOH}, \mathrm{KOH}, \mathrm{Na}-\mathrm{Si}$ and $\mathrm{K}-\mathrm{Si}$ activators, following the same mixture procedure described earlier. The results for compressive strength can be observed in Figure 1 and the results for flexural strength in Figure 2. 


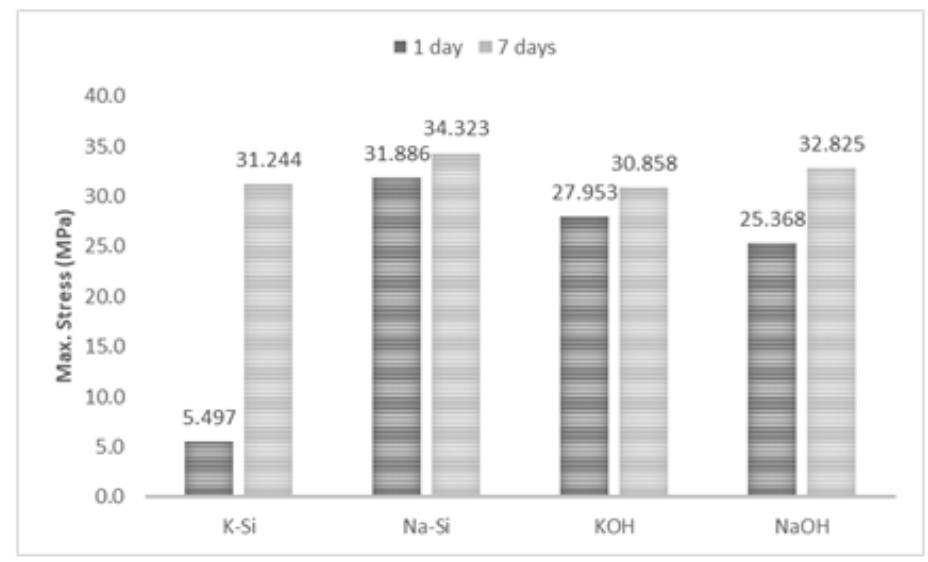

Fig. 1. Maximum stress for compressive strength (MPa) results for different activating solutions.

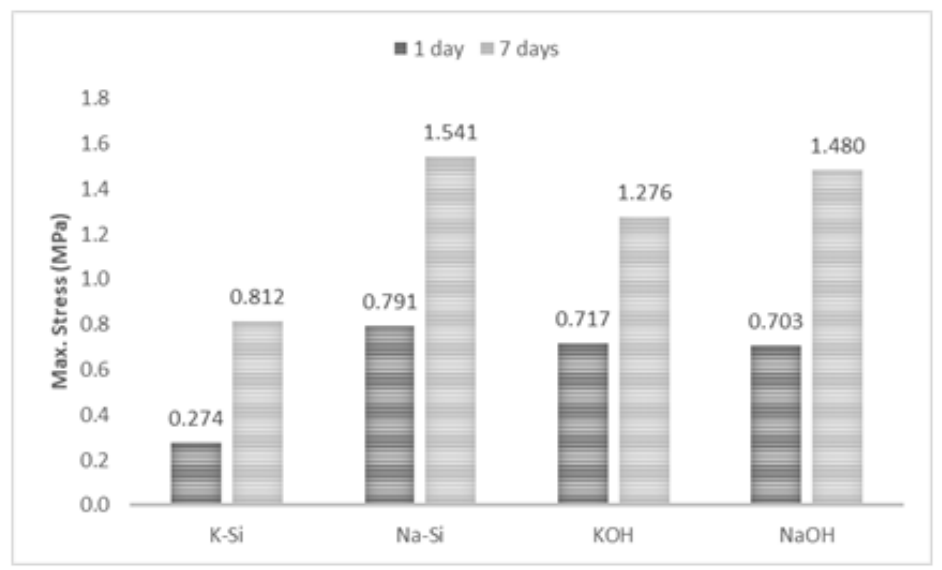

Fig. 2. Maximum stress (MPa) for flexural strength results for different activating solutions.

The effect of different activating solutions types is apparent by comparing one day results. It can be observed that for one day, the mixture with $\mathrm{Na}-\mathrm{Si}$ activating solution had results for compressive strength $86.5 \%$ higher than the mixture with $\mathrm{K}-\mathrm{Si}$ activating solution, $31.1 \%$ higher than the $\mathrm{KOH}$ solution and $37.5 \%$ higher than the $\mathrm{NaOH}$ solution. As for flexural strength results, it can be observed for one day curing a difference of $82.2 \%$ between the two types of silica activating solution. Comparing $\mathrm{Na}-\mathrm{Si}$ with $\mathrm{KOH}$, the reduction was $1.9 \%$ for flexural strength, and comparing with $\mathrm{NaOH}, 54.4 \%$.

When analyzing 7 days compressive strength results, the difference between the two silica activating solutions is much lower, reaching 30.1\%. When comparing results for $\mathrm{KOH}$ and $\mathrm{NaOH}$ with $\mathrm{Na}-\mathrm{Si}$, a reduction of $17.0 \%$ and $26.6 \%$ can be observed, respectively. As for the flexural strength essays, the difference is $61.8 \%$ for the silica activating solutions. And comparing $\mathrm{KOH}$ and $\mathrm{NaOH}$ with $\mathrm{Na}-\mathrm{Si}$, the reduction presented is $10.4 \%$ and $30.3 \%$.

The results between one and seven days for the $\mathrm{Na}-\mathrm{Si}$ solution had a variation of $9.2 \%$, while for $\mathrm{K}-\mathrm{Si}$ it was $82.4 \%$, for $\mathrm{KOH} 24.7 \%$ and $22.7 \%$ for $\mathrm{NaOH}$. Therefore, it can be deduced that the geopolymerization of the K-Si mixture is slower than when using the other solutions proposed in this study. By analyzing the results on the effect of activating solution, Na-Si solution was chosen to study different formulations, due to its higher mechanical properties and faster geopolymerization process. 
According Duxson et. al 22, the compressive strengths of potassium-based geopolymer are usually higher than sodium-based geopolymer, contrary to this study. Therefore, it can be deduced that different sources of GBFS have an impact on the compressive strength and geopolymerization process.

\subsection{Effect of different formulations}

\subsubsection{Mechanical properties}

For the evaluation of mechanical properties, new mixtures for three different formulations were tried, following suggestions from Al-Majidi et. al (2016) 37. According to the results on the previous section, Na-Si solution was chosen to evaluate the effect of the different formulations. The new formulations had solid-to-liquid ratios of 1.5, 2.0 and 2.2, obtained by dividing the total of precursor material, in mass, by the sum of water and activating solution. The formulations used were presented in Table 4. Three specimens of each formulation were tested for compressive strength and flexural strength at 7, 14, 28 and 90 days. Results can be observed in Figure 3 and Figure 4, respectively.

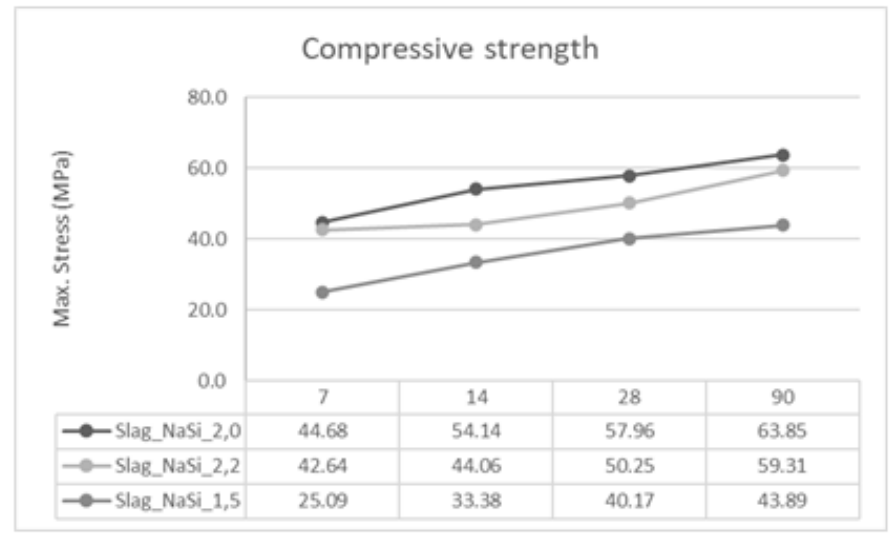

Fig. 3. Maximum stress for compressive strength results for different formulations at 7, 14, 28 and 90 days.

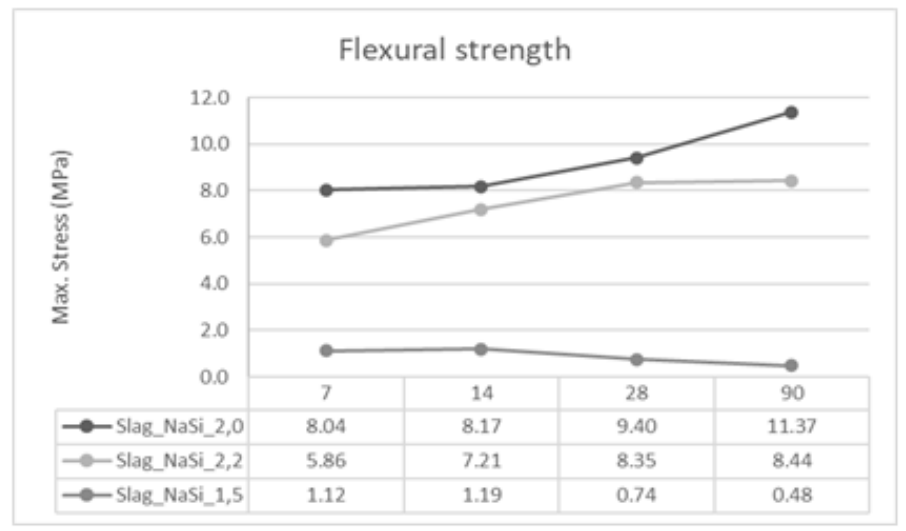

Fig. 4. Maximum stress for flexural strength results for different formulations at 7, 14, 28 and 90 days. 
It is important to notice that the percentages of precursor where around $70 \%$ for each formulation, the variations where restrained to water and activating solution. The comparison shows that the compressive strength and flexural strength is $9 \%$ lower when comparing the solution $2.2(\mathrm{~S} / \mathrm{L})$ with the $2.0(\mathrm{~S} / \mathrm{L})$. This is attributed to the higher volume of solids in the formulation, which increased the number of voids in the sample. Therefore, it can be deduced that the higher S/L ratio not only affects the reaction between activating solution and precursor, which may reduce the compressive strength, but it can also affect the durability 38 due to high apparent voids.

The comparison between the solution $1.5(\mathrm{~S} / \mathrm{L})$ and solution $2.0(\mathrm{~S} / \mathrm{L})$ shows and reduction of $65 \%$ in the compressive strength and $86 \%$ in the flexural strength. A more fragile material can be caused because of a lower polymerization rate. It can be deduced that, at 7 days, not all the GBFS had been activated. This will be showed by the SEM observations on the next section. Kamalloo et. al 38 also observed that increasing $\mathrm{H}_{2} \mathrm{O} / \mathrm{M}_{2} \mathrm{O}$ ratios, corresponding to increasing the amount of water, lowers mechanical performance.

For investigating the physical properties, three rectangular specimens with dimensions $40 \times 40 \times 160 \mathrm{~mm}$ were casted of each of the formulations presented in Table 4, according to the procedures explained in the materials section above. The variation in length of the specimen was measured for 28 days to determine the shrinkage for ambient temperature curing. The mass and elastic properties were also measured for 28 days to observe the stabilization of their value. The results for these measurements after 28 days can be observed in Table 5 .

Table 5. Physical properties for geopolymer samples.

\begin{tabular}{|l|l|l|l|l|l|l|l|}
\hline $\mathbf{S} / \mathbf{L}$ & $\begin{array}{c}\mathbf{H}_{2} \mathbf{O} \\
\left(\mathbf{k g} / \mathbf{m}^{\mathbf{3}}\right)\end{array}$ & $\begin{array}{c}\text { Length } \\
(\mathbf{c m})\end{array}$ & $\begin{array}{c}\text { Mass } \\
(\mathbf{g})\end{array}$ & $\begin{array}{c}\text { Density } \mathbf{\rho} \\
\left(\mathbf{g} / \mathbf{c m}^{\mathbf{3}}\right)\end{array}$ & $\begin{array}{c}\text { Young } \\
\text { Modulus } \\
(\mathbf{M P a})\end{array}$ & $\begin{array}{c}\text { Dynamic } \\
\text { Modulus } \\
(\mathbf{M P a})\end{array}$ & $\begin{array}{c}\text { Poisson } \\
\text { ratio }\end{array}$ \\
\hline 2.2 & 260.4 & 15.99 & 498.45 & 1.95 & 18.95 & 7.87 & 0.20 \\
\hline 2.0 & 208.3 & 15.95 & 393.12 & 1.54 & 6.00 & 2.86 & 0.10 \\
\hline 1.5 & 244.1 & 15.98 & 520.41 & 2.04 & 15.92 & 6.41 & 0.23 \\
\hline
\end{tabular}

The differences obtained in the Poisson ratio are due to the difference of elasticity between the different formulations. A higher Young modulus means a material requires higher stress to stretch a material the same distance as a material with a lower Young modulus 39. According to the volume of water added to the mixture, workability properties of the materials can vary 40, observed in density and elastic properties functions of the mixtures tested. According to Autef et. al, 41, the rate of trapped water on the geopolymer network can reduce mechanical properties due to higher porosity.

\subsubsection{Scanning Electron Microscopy (SEM) observations}

The Scanning Electron Microscopy (SEM) observations were conducted to observe the microstructure and geopolymerization process of the three formulations subjected to 7 days compressive strength essay for investigating the effect of different formulations, reported in section 3.2.2.

The SEM images can be observed in Figure 5 and Figure 6, along with the respective EDS results for the $1.5(\mathrm{~S} / \mathrm{L})$ formulation. By analyzing the EDS results and the composition for each point studied, the blast furnace slag, which has not yet reacted, can be observed in Figure 5, with major concentrations of Calcium (Ca), Silicon ( $\mathrm{Si}$ ) and Aluminum ( $\mathrm{Al})$. Figure 6 presents the activating solution $\mathrm{Na}-\mathrm{Si}$, with higher concentrations of Sodium $(\mathrm{Na})$ and Silicon $(\mathrm{Si})$ showed by the EDS. Thus, the GBFS has not been yet activated by the $\mathrm{Na}-\mathrm{Si}$ solution after 7 days, as reported in the previous section. 


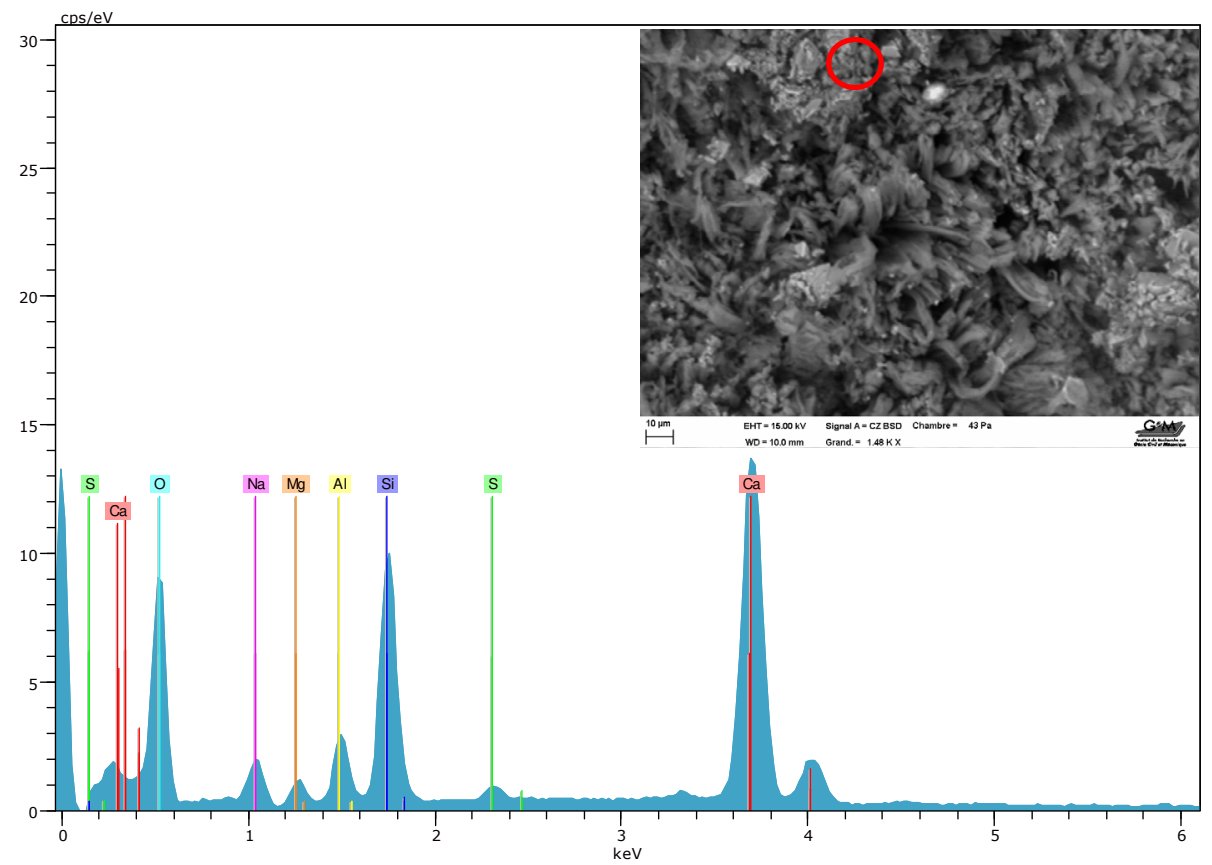

Fig. 5. SEM observation for early stage geopolymerization - formulation 1,5 (S/L) (blast furnace slag).

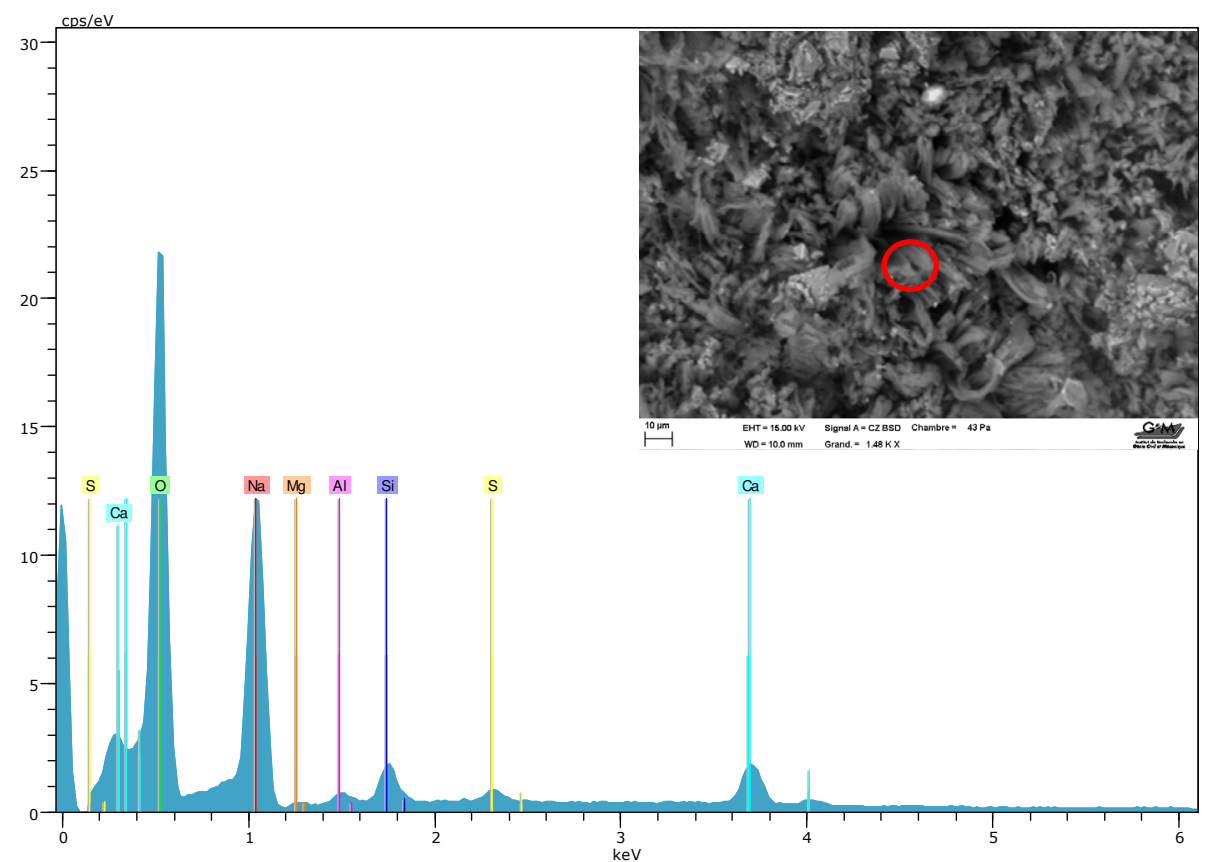

Fig. 6. SEM observation for early stage geopolymerization - formulation 1,5 (S/L) (activating solution $\mathrm{Na}-\mathrm{Si}$ ).

As concluded by Gruskovnjak et. al 42, Wang et. al 43 and van Deventer et. al 14, alkali activated GBFS produces calcium silicate hydrate (CSH), hydrotalcite $\left(\mathrm{Mg}_{6} \mathrm{Al}_{2} \mathrm{CO}_{3}(\mathrm{OH})_{16} .4 \mathrm{H}_{2} \mathrm{O}\right)$, calcite $\left(\mathrm{CaCO}_{3}\right)$ and $\mathrm{AFm}$ ettringite of general formula 
$\left.\left[\mathrm{Ca}_{2} .(\mathrm{Al}, \mathrm{Fe})(\mathrm{OH})_{6}\right)\right] \cdot \mathrm{X} \cdot \mathrm{nH}_{2} \mathrm{O}$ (X being a singly charged anion). In Figure 7 the point selected presents a high concentration of Calcium (Ca), Silicon ( $\mathrm{Si}$ ), Aluminum (Al), Carbon (C), Magnesium (Mg) and Sulfur (S). According to the products observed by the EDS, it can be deduced that the point evaluated corresponds to alkali activated GBFS. Thus, for the same age, the geopolymerization of the formulation 2.0 has a better geopolymerization process than the formulation 1.5 .

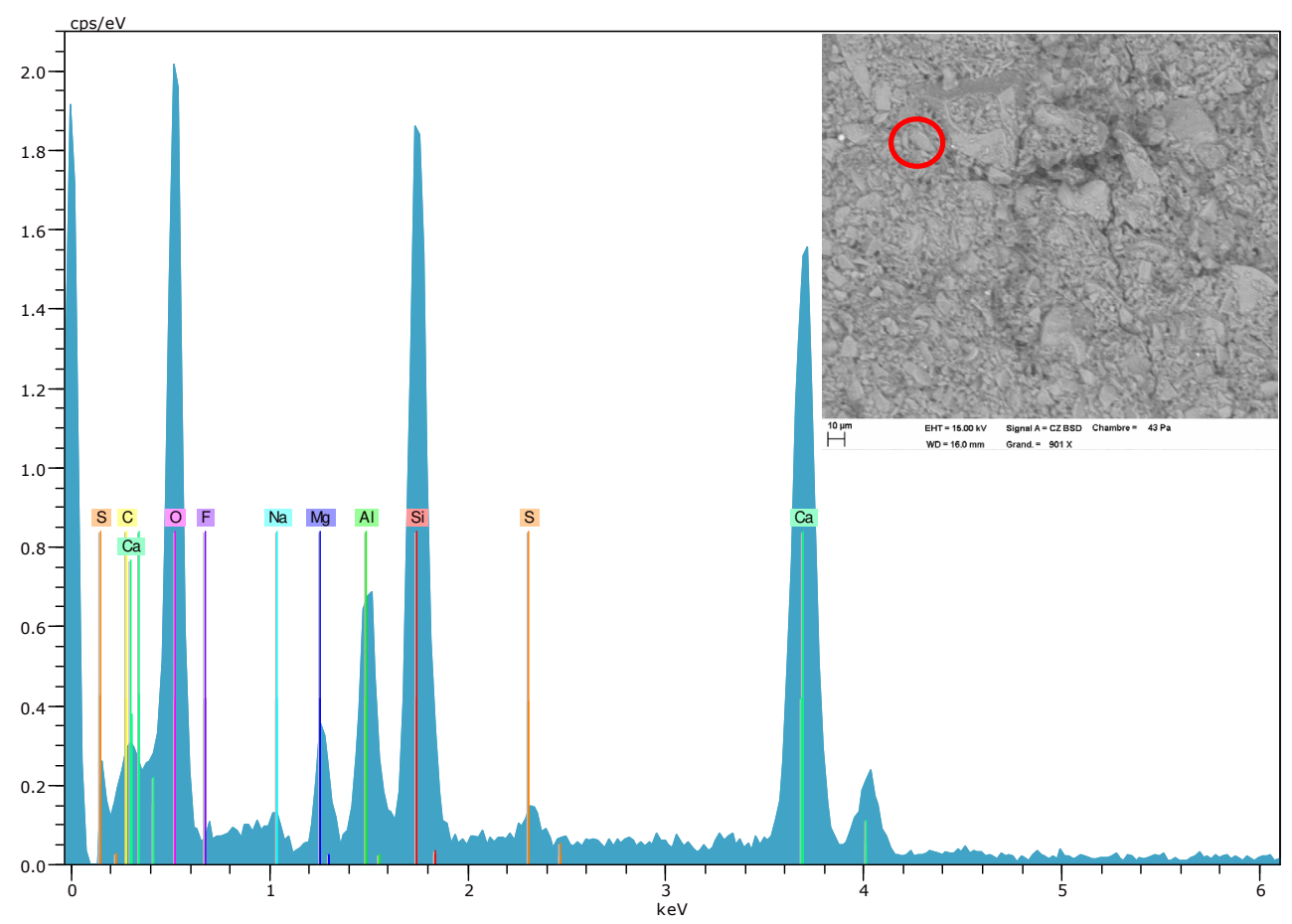

Fig. 7. SEM observation for early stage geopolymerization - formulation $2.0(\mathrm{~S} / \mathrm{L})$.

In Figure 8 the mixture $2.2(\mathrm{~S} / \mathrm{L})$ is presented, and the same pattern of products is observed, but with a higher concentration of Calcium (Ca). Also in Figure 8 the voids can be observed as part of the curing process and the elevated portion of GBFS not reacted can support the conclusion of the previous section that higher $\mathrm{S} / \mathrm{L}$ ratio affects the reaction between activating solution and precursor and the durability due to high apparent voids 


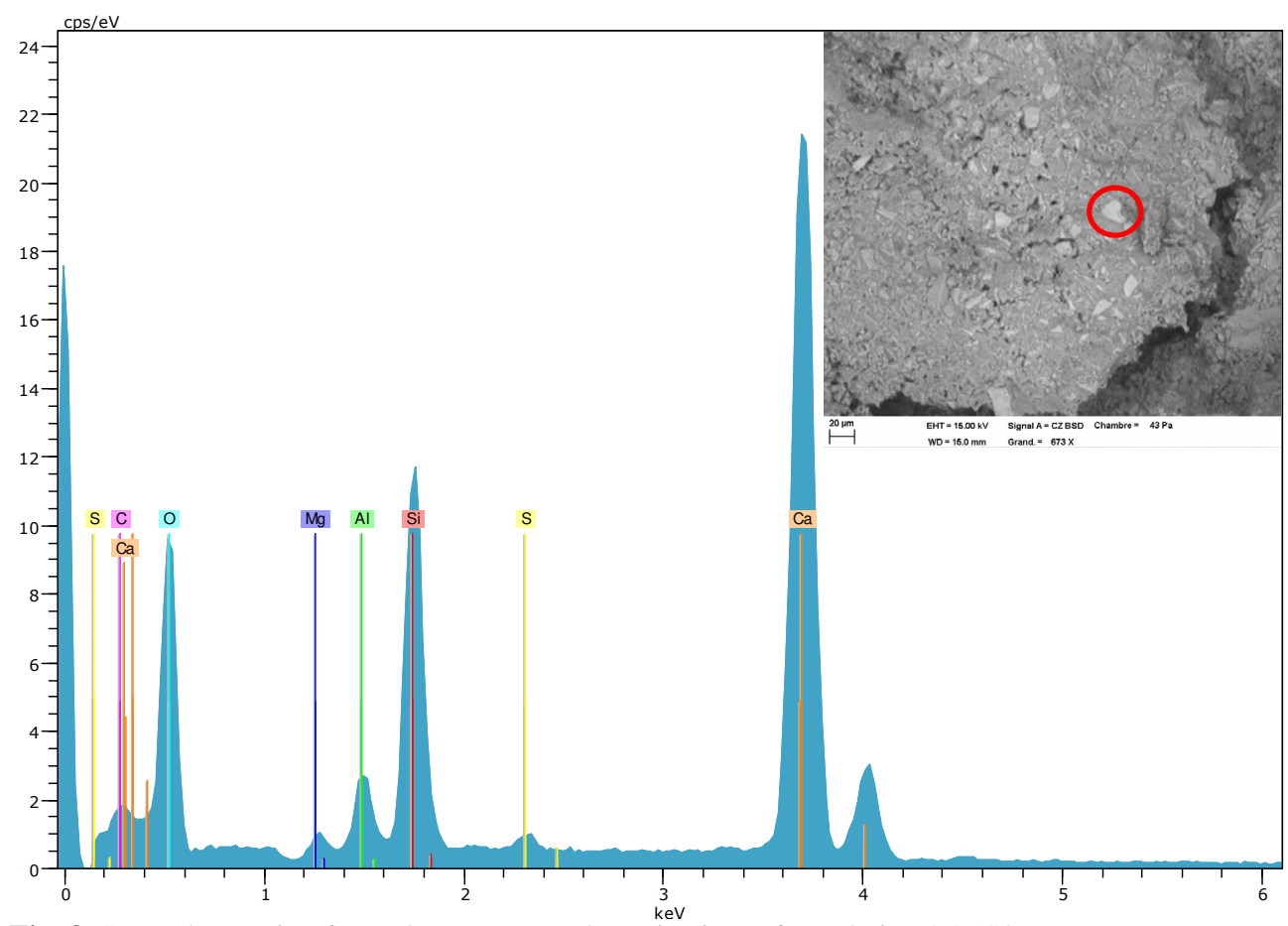

Fig. 8. SEM observation for early stage geopolymerization - formulation $2.2(\mathrm{~S} / \mathrm{L})$.

\section{Concluding remarks}

The experimental studies performed aimed to study the effect of activating solution and different formulations on the geopolymerization process for GBFS alkali-activated geopolymers. For this purpose, different activating solutions were tested for compressive strength in one and seven days. Analyzing the results for the effect of activation solution type, it was concluded that the solution that presented the best geopolymerization process was Na-Si. A compressive strength of $71.492 \mathrm{kN}$ was reached after 7 days, at least $17 \%$ higher than the other activating solutions studied. The second stage of this research was to analyze the effect of the different formulations on the geopolymerization process. As the activating solution that had the best results in the first stage, Na-Si activating solution was used on this stage, with variations on $\%$ of water and solid-to-liquid ratios. There are direct relationships between the parameters evaluated, durability and the geopolymerization process, observed on the mechanical, physical. The formulation that presented the best compressive strength results had an $\mathrm{S} / \mathrm{L}$ ratio of 2.0 , reaching $84.882 \mathrm{kN}$. Finally, the microscopic structure of the different formulations was studied to relate with the compressive strength results.

The authors acknowledge the Brazilian institutions CAPES (Coordenação de Aperfeiçoamento de pessoal de nível superior - Coordination of Improvement of senior staff), CNPq (Conselho Nacional de Desenvolvimento Científico e Tecnológico - National Council for Scientific and Technological Development) and Institut de Recherche en Génie Civil et Mécanique - Research Institute on Civil and Mechanical Engineering for the financial support and their support in conducting experiments. 


\section{References}

1. J. L. Provis, Mater. Struct. 47, 11-25 (2014)

2. J. L Provis et. al., Geopolymers: structures, processing, properties and industrial applications (Elsevier, 2009)

3. J. Davidovits, Geopolymer 99 (France, 1999)

4. L. Alves, A. Nogueira, J. Santos, S. Barros, Res. Dev. Material Sci. 12 (2019)

5. J. L. Provis, J.S.J. Deventer, RILEM State-of-the-Art Reports 13 (2014)

6. P. H. R. Borges et. al., Ambiente Construído, 14, 153-168 (2014)

7. J. Davidovits, Geopolymer 2002 Conference (France, 2002)

8. E. I. Diaz, E. N. Allouche, S. Eklund, Fuel, 89, 992-996 (2010)

9. D. Hardjito, S. E. Wallah, D.M.J. Sumajouw, B. V. Rangan, ACI Mater. J. 101, 467472 (2004)

10. N. Jambunathan et. al., Cem. Concr. Res. 54, 143-150 (2013)

11. D. Hester, C. McNally, M. Richardson, Constr. Build. Mater. 19, 661-665 (2005)

12. S. de Barros, J. R. De Souza, K. C. Gomes, E. M. Sampaio, N. P Barbosa, S. M. Torres, J. Adhes. 88, 364-375 (2012)

13. F. Pacheco-Torgal, D. Moura, D. Y. Ding, S. Jalali, Constr. Build. Mat. 25, 3732-3745 (2011)

14. J. S. J. van Deventer et. al., J. Sustain. Cem-Based Mater. 4, 116-128 (2015)

15. K. Sagoe-Crentsil, T. Brown, A. Taylor, J. Sustain. Cem-Based Mater. 2, 35-42 (2013)

16. S. R. Rego, K. C. Gomes, M. Rosas, S. M. Torres, S. de Barros, J. Adhes. 90, 120-133 (2014)

17. A. Fernández-Jimánez, J. Palomo, F. Puertas, Cem. Concr. Res. 29, 1313-1321 (1999)

18. T. Bakharev, J. Sanjayan, Y. B Cheng, Cem. Concr. Res. 33, 1607-1611 (2003)

19. C. Shi, J. Stegemann, Cem. Concr. Res. 30, 803-808 (2000)

20. S. A. Bernal, E. D. Rodríguez, R. Mejía de Gutiérrez, J. L. Provis, J. Sustain. CemBased Mater. 1, 138-151 (2012)

21. R. J. Myers, S.A. Bernal, J.L Provis, Cem. Concr. Res. 66, 27-47 (2014)

22. P. Duxson, J. L. Provis, G. C. Lukey, S. W. Mallicoat, W. M. Kriven, J. S. J. van Deventer, Colloid Surface A. 269, 47-58 (2005)

23. S. Caijun, S. Zhenguo, H. Xiang, Z. Rui, C. Linlin, Mat. and Struct. 48 (2015)

24. A. Palomo, M. W. Grutzeck, M. T. Blanco, Cem. Concr. Res. 29, 1323-1329 (1999)

25. H. Xu, J. S. J. van Deventer, Int. J. Miner. Process 59, 247-266 (2000)

26. J. C. Swanepoel, C. A. Strydom, Appl. Geochem. 17, 1143-1148 (2002)

27. V. F. F. Barbosa, K. J. D. MacKenzie, C. Thaumaturgo, Int. J. of Inorg. Mater. 2, 309317 (2000).

28. C. Shi, P. Krivenko, D.M. Roy, Alkali-activated cements and concretes. (Taylor and Francis, Abingdon, UK, 2006)

29. H. Xu, J. S. J. Deventer, Geopolymerisation of Multiple Minerals. Miner. Eng. 15, 1131-1139 (2002)

30. D. Hardjito, B. Rangan, Development and Properties of Low-calcium Fly Ash Based Geopolymer Concrete. (Research Report. Curtin University of Technology, 2005) 
31. P. Duxson, A. Fernándes-Jiménez, J. L. Provis, G.C. Lukey, A. Palomo, J.S.J. Devener, J. Mater. Sci. 42, 2917-2933 (2007)

32. P. Duxson, S.W. Mallicoat, J.L. Lukey, W. Kriven, J.S.J. van Deventer, Colloid Surface A. 292, 8-20 (2007)

33. P. Duxson, J.L. Provis, Designing Precursors for Geopolymer Cements. J. Am. Ceram. Soc. 91, 3864-3869 (2008)

34. N. A. Lateef, E. Deaver, K. E. Mohamed, P. Ziehl, Constr. Build. Mater. 112, 807-815 (2016)

35. I. Moghrabi, Modeling of the mechanical behavior of treated sediments and study of a new way of their valorization by geopolymers, Thesis. (Universite de Nantes, 2018)

36. J. Davidovits, R. Davidovits, M. Davidovits, Geopolymeric cement based on fly ash and harmless to use (2012)

37. M. H. Al-Majidi, A. Lampropoulos, A. Cundy, S. Meikle, Development of geopolymer mortar under ambient temperature for in situ applications. Constr. Build. Mater. 120, 198-211 (2016)

38. A. Kamalloo, Y. Ganjkhanlou, S.H. Aboutalebi, H. Nouranian, Int. J. Eng. 23, 145-452 (2010)

39. S. Ridha, A.I. Abd Hamid, A.H. Abdul Halim, N.A. Zamzuri, IOP Conf. Ser.: Earth Environ. Sci. 140 (2018)

40. M. Stevenson, K. Sagoe-Crentsil, J. Mater. Sci, 40, 2023 (2005)

41. A. Autef, E. Joussein, A. Poulesquen,G. Gasgnier, S. Pronier, I. Sobrados, J. Sanz, S. Rossignol, J. Colloid. Interf. Sci. 408, 43-53 (2013)

42. A. Gruskovnjak, et. al, Adv. Cem. Res. 18, 119-128 (2006)

43. S. D. Wang, K. L. Scrivener, Cem. Concr. Res. 25, 561-571 (1995) 